\title{
The Effect of Pressure Losses on Measured Compressor Efficiency
}

\author{
Kristoffer Ekberg Lars Eriksson \\ Vehicular Systems, Linköping University, Sweden, \{kristoffer.ekberg, lars.eriksson\}@liu.se
}

\begin{abstract}
While measuring the compressor behavior at different load points in for example a gas stand, the inlet and outlet pressures are not always measured directly before and after the compressor. The friction inside the pipes and the physical piping configuration affect the measured compressor efficiency, due to the induced change of fluid enthalpy. If the measured pressures at the end of the inlet and outlet pipes are not the same as the actual pressure before and after the compressor, the acquired compressor map does not give the right description of it as an isolated component. The main contribution of this paper is the analysis of the impact of gas stand energy losses due to pipe friction on the compressor map. As a result the paper suggests a way to take the pressure losses in the inlet and outlet pipes into account. The suggested model takes pipe friction, diffuser, nozzle and pipe bends into account. The potential measurement error in compressor efficiency due to energy losses in the pipes in this experiment is $2.7 \%$ (percentage points) at maximum mass flow of air through the compressor.
\end{abstract}

Keywords: gas stand, pipe, bend, diffuser

\section{Introduction}

Gas stand testing of turbochargers is a time consuming process where one of the goals is to determine the compressor efficiency. Turbochargers are modeled in computers to perform more cost efficient tests and experiments. Softwares today are used to solve and compute the dynamic behaviors of complex engine systems involving turbochargers. Turbocharger models are often adjusted to fit measured data, from for example a gas stand test. Most of the analysis assume that the turbocharger models represent the turbocharger as a single component. This means that to have accurate turbocharger models, the measurement data should represent the turbocharger only, and not include any pipes or other objects connected to the turbocharger housing. The pipes in a gas stand, connecting the turbocharger to measurement instruments, induces errors into the computer models if the data is used without correction. Since the pressures and temperatures are measured some distance away from the actual inlet and outlet on the compressor, the physical setup of the gas stand may need to be accounted for to get a more accurate result of the compressor efficiency. In both the inlet and outlet pipes there are pressure losses due to friction inside the pipes, also if the gas flow path contains bends or area changes, these could induce pressure losses. There are different ways to develop a gas stand (see for example (Venson et al., 2006) or (Young and Penz, 1990)), the idea is to simulate engine conditions to find the turbocharger characteristics. When making measurements in a gas stand, the monitoring of the pressures and temperatures before and after the compressor are important to get accurate results of the compressor efficiency (Kumar et al. 2014). The compressor efficiency is determined by using measured values of temperatures and pressures before and after the compressor. Studies with focus on the heat transfer inside the turbocharger (Nick Baines and Karl D.Wygant and Antonis Dris, 2009) and how the heat transfer affects the compressor efficiency have been performed (Marelli et al., 2015), while others focusing on the possible measurement errors due to sensor inaccuracy (Guillou. 2013). No papers are found where the actual placement of the sensors are examined up or downstream from the compressor, SAE standard J1826 recommends placing the static pressure taps 2 to 3 pipe diameters downstream of the rotor (SAE, 1995). The sensor placement is crucial to achieve a reliable result during testing. Different test rigs may give different results due to environmental conditions, if the inlet air is not conditioned, the efficiency uncertainty will fluctuate (Guillou, 2013). The impact from inlet air being dry or humid on compressor efficiency has been studied in (Serrano et al., 2009), the impact is small and should only be considered if very high accuracy is wanted. The enthalpy loss between the measurement positions and the compressor due to the pressure loss indicates that the compressor efficiency is actually better than measured.

\subsection{Contributions}

This paper is the first to analyze the gas stand pressure losses. The effects of the pressure losses on measured compressor efficiency are analyzed and ways to compensate for them are developed. Influences of the gas stand pressure losses are displayed on the compressor map.

\subsection{Setup for the analysis}

The main scope of the paper is to show how the change of enthalpy in the inlet and outlet pipes affect the compressor efficiency. The inlet and outlet enthalpies $\left(\dot{h}_{\text {in }}\right.$ and $\dot{h}_{\text {out }}$ in Figure 1) are not the enthalpies actually entering and leaving the turbocharger compressor, the actual values are $\dot{h}_{\text {in }}^{\prime}$ and $\dot{h}_{\text {out }}^{\prime}$, which are corrected to exclude the friction in the inlet and outlet pipes $\left(\dot{w}_{f, p i p e, i n}\right.$ ăand $\left.\dot{w}_{f, p i p e, o u t}\right)$. In 
equation (1a) the work used by the compression process is described as it is used today, where the connecting inlet and outlet pipes are included, since the measurement positions are not located directly at the inlet or outlet of the compressor. Equation (1b) describes the work required by the compressor as a single component, describing the compression work made by the turbocharger compressor only.

$$
\begin{array}{r}
\dot{w}_{c, \text { Old }}=\dot{w}_{\text {compression }}+\dot{w}_{f, \text { pipe }}+\dot{w}_{f, \text { pipe }} \\
\dot{w}_{c, \text { New }}=\dot{w}_{\text {compression }}
\end{array}
$$

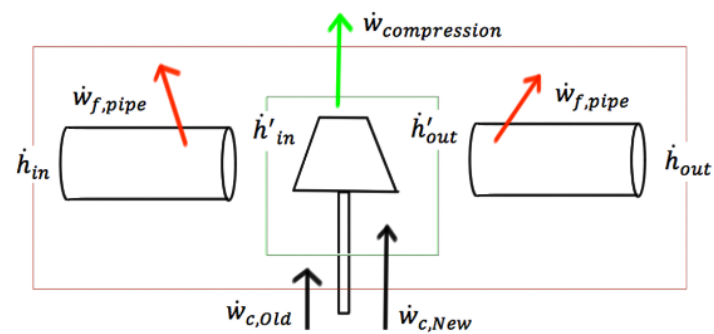

Figure 1. Energy flow in the compressor. The outer box (red) represents the system that is measured in a gas stand, the inner box (green) is the preferred system that is to be described by the model.

To quantify the impact from the inlet and outlet pipe frictions ( $\dot{w}_{f, p i p e, \text { in }}$ and $\left.\dot{w}_{f, p i p e, \text { out }}\right)$ on the measured compressor efficiency, three cases are investigated. The three cases investigates:

1. straight inlet and outlet pipes, see Figure 2. The diameter of the pipes $\left(d_{\text {inlet }}\right.$ and $\left.d_{\text {outlet }}\right)$ are assumed to be equal to the compressor inlet and outlet diameters $\left(d_{c, \text { inlet }}\right.$ and $\left.d_{c, \text { outlet }}\right)$.

2. using pipes with diffuser and nozzle. See Figure 3

3. adding a $90^{\circ}$ smooth bend on the inlet pipe. See Figure 4

\subsection{Experimental data}

Data used during the analysis is a measured compressor map from a commercial turbocharger, the measured mass flow range $[0,0.21] \mathrm{kg} / \mathrm{s}$ and pressure ratio between [1, 2.8] $\frac{p_{02}}{p_{01}}$. The sensor errors effect on the achieved results from a gas stand have been studied in (Guillou, 2013). The measured data used in this analysis are assumed to be correct, i.e. all measured values are assumed to be perfect, no sensor errors are assumed to be present.

\subsection{Compressor Map}

One of the main ideas behind testing the turbocharger in a gas stand is to determine the compressor efficiency and flow characteristics at different work points. The compressor behavior is presented on a compressor map, where the corrected compressor mass flow and pressure ratio defines

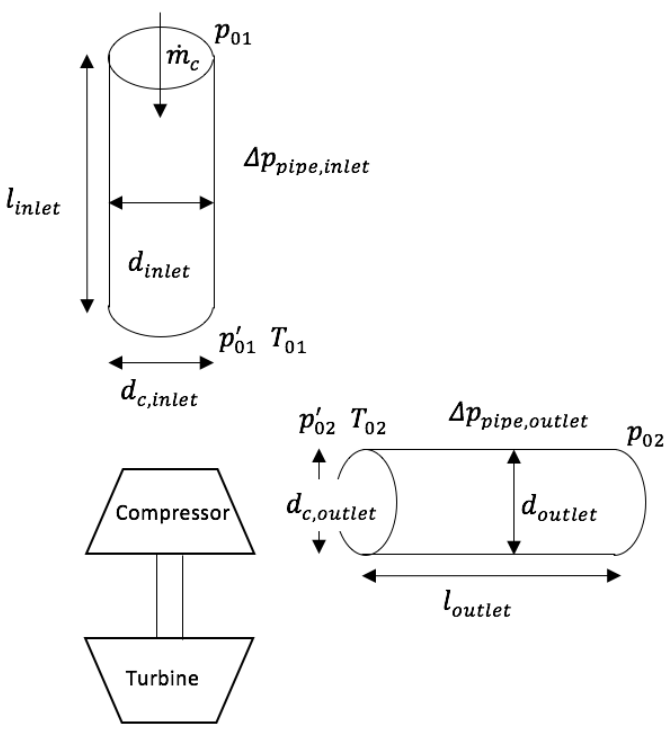

Figure 2. Pressure drops are represented by $\Delta p_{n}$, the total pressures by $p_{01}$ and $p_{02}$, the corrected total pressures by $p_{01}^{\prime}$ and $p_{02}^{\prime}$ and the measured temperatures by $T_{01}$ and $T_{02}$. The mass flow of air inside the pipes are represented by $\dot{m}_{c}$. The physical dimensions on pipe lengths and pipe diameters are described by $l_{n}$ and $d_{n}$.

a plane where the compressor efficiency is displayed. In the evaluation of the results, the effects from the pressure losses on compressor efficiency are presented on the compressor map. The reference compressor efficiency is calculated using measured data, and later recalculated when taking the pressure losses in the gas stand into account.

\subsection{Compressor Isentropic Efficiency}

The compressor isentropic efficiency is defined as the smallest amount of power needed to compress the air without heat exchange with the environment (isentropic process), divided by the actual amount of power consumed by the process. Using measured total temperatures and total pressures (calculated from static pressures, see equation (4)) from a gas stand, the compressor total to total isentropic efficiency can be calculated using equation (2). (Eriksson and Nielsen, 2014)

$$
\eta_{c}=\frac{\Pi_{c}^{\frac{\gamma-1}{\gamma}}-1}{\frac{T_{02}}{T_{01}}-1}, \text { where } \Pi_{c}=\frac{p_{02}}{p_{01}}
$$

where $p_{01}$ and $p_{02}$ are total pressures, $T_{01}$ and $T_{02}$ are total temperatures and $\gamma$ is the ratio of specific heats (assumed to be constant).

\subsection{Corrected Mass Flow}

Corrected mass flow is used to display the mass flow in the compressor map. The corrected mass flow is used instead of the measured mass flow, to take surrounding conditions during measurements into account. The surrounding conditions are the reference temperature, $T_{r e f}$ and the refer- 


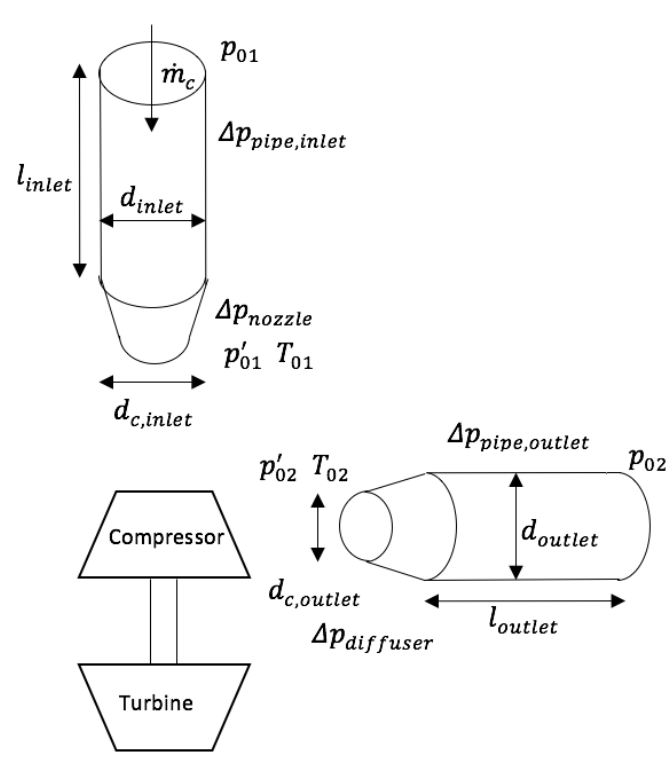

Figure 3. Pressure drops are represented by $\Delta p_{n}$, the total pressures by $p_{01}$ and $p_{02}$, the corrected total pressures by $p_{01}^{\prime}$ and $p_{02}^{\prime}$ and the measured temperatures by $T_{01}$ and $T_{02}$. The mass flow of air inside the pipes are represented by $\dot{m}_{c}$. The physical dimensions on pipe lengths and pipe diameters are described by $l_{n}$ and $d_{n}$.

ence pressure, $p_{\text {ref }}$. The corrected mass flow is calculated according to equation (3). (Eriksson and Nielsen, 2014)

$$
\dot{m}_{c, c o r r}=\frac{\dot{m}_{c} \sqrt{\frac{T_{01}}{T_{r e f}}}}{\frac{p_{01}}{p_{r e f}}}
$$

\subsection{Data Treatment}

The pressures and temperatures used when calculating the compressor efficiency should be the total pressures and total temperatures. The relation between the measured static pressure $p_{i}$ and the total pressure $p_{0 i}$ is displayed in equation $\left[4\right.$, , where $C_{i}=\frac{\dot{m}_{c}}{\rho_{i} A}$ is the fluid velocity inside pipe i.

$$
p_{0 i}=p_{i}+\frac{\rho_{i} C_{i}^{2}}{2}
$$

To convert the measured total temperature $T_{0 i}$ to static temperature $T_{i}$ equation (5) from (Eriksson and Nielsen, 2014) can be used.

$$
T_{i}=\frac{A^{2} p_{i}^{2} c_{p}}{R^{2} \dot{m}_{c}^{2}}\left(\sqrt{1+2 \frac{R^{2} \dot{m}_{c}^{2} T_{0 i}}{A^{2} p_{i}^{2} c_{p}}}-1\right)
$$

where $\dot{m}_{c}$ is the mass flow of air through the pipe, $\rho_{i}$ is the air density and $\mathrm{A}$ is the cross section area of the pipe at the measurement position. The air inside the system is treated as an ideal gas, following this assumption, the density is calculated using equation (6). (Eriksson and Nielsen, 2014)

$$
\rho_{i}=\frac{p_{i}}{R T_{i}}
$$

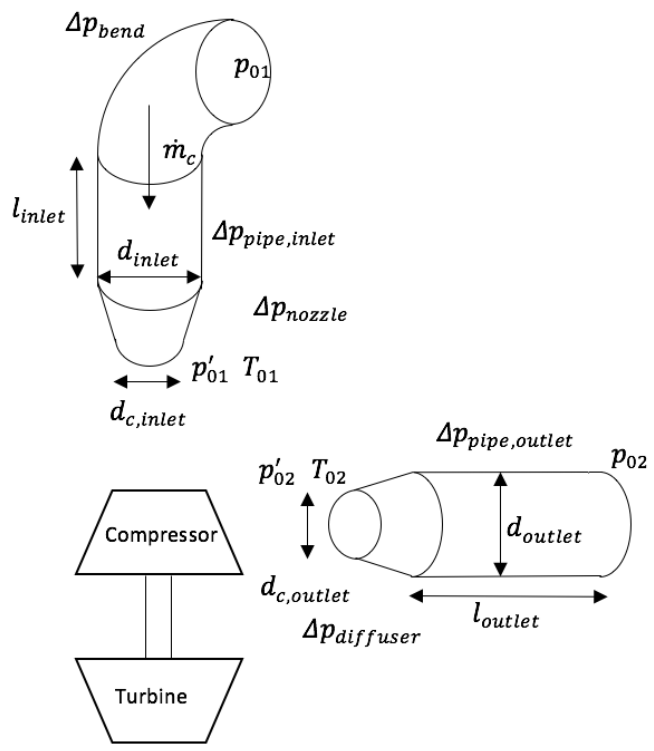

Figure 4. Pressure drops are represented by $\Delta p_{n}$, the total pressures by $p_{01}$ and $p_{02}$, the corrected total pressures by $p_{01}^{\prime}$ and $p_{02}^{\prime}$ and the measured temperatures by $T_{01}$ and $T_{02}$. The mass flow of air inside the pipes are represented by $\dot{m}_{c}$. The physical dimensions on pipe lengths and pipe diameters are described by $l_{n}$ and $d_{n}$.

\section{Pressure Losses in Gas Stand}

Pressure losses in different piping systems and pipe configurations have been examined for many years. The formulas and expressions are empirical or semi-empirical correlations that are created from experiments to describe specific objects or system configurations. The different pressure losses in different parts in the gas stand are calculated according to empiric formulas, these formulas are valid for fully developed turbulent flow, the turbulent flow in the parts taken into account is therefor assumed to be fully developed. Both the total temperature and the density of the fluid are assumed to be constant along the inlet and outlet pipe sections.

\subsection{Pressure Loss in Straight Pipe}

Straight pipes in for example a gas stand causes pressure losses due to friction inside the pipes. The selection of pipe material and manufacturing method of the pipes are important to get a low friction pipe. The surface roughness inside the pipe induces pressure loss when the flow is turbulent, when the flow is laminar, the friction factor $f_{\text {pipe }, i}$ is independent of the surface roughness. The pressure loss in a straight pipe is calculated with equation (7) (Cengel et al., 2008).

$$
\Delta p_{\text {pipe }}=f_{\text {pipe }, i} \frac{l_{i}}{d_{i}} \frac{\rho_{i} v_{i}^{2}}{2}
$$

Where $f_{\text {pipe }, i}$ is a friction factor, $\rho_{i}$ is the density of the fluid inside the specific pipe section $i, l_{i}$ is the pipe section length, $v_{i}$ is the mean velocity of the fluid inside the 
specific pipe section $i$. The friction factor $f_{\text {pipe }, i}$ is dependent on the flow characteristics inside the pipe. The flow characteristics could be either laminar or turbulent. The flow characteristics inside the pipes are determined by Reynolds number, $R e$. Reynolds number is calculated according to equation (8). (Cengel et al. 2008)

$$
R e=\frac{v_{i} d_{i} \rho_{i}}{\mu_{i}}
$$

Where $v_{i}$ is the mean velocity of the fluid inside the pipe, $\rho_{i}$ is the fluid density, $d_{i}$ is the hydraulic diameter (hydraulic diameter equals pipe diameter for circular pipes) and $\mu_{i}$ is the dynamic viscosity of the fluid. The dynamic viscosity of air is described as a function of air temperature:

$$
\mu_{i}=\mu\left(T_{i}\right)
$$

According to (White, 1999), the change in $\mu$ is around $10 \%$ for air when the pressure is increased from 1 to 50 atm, and that it is customary in most engineering work to neglect the pressure variations. The viscosity of a gas is by (Massey and Ward-Smith, 1998) said to be independent of its pressure (except at very high or very low pressures). In this study, the change in pressure ranges from around 1 bar to 2.85 bar, therefore the fluid dynamic viscosity is assumed to be independent of the pressure variations. The function in equation (9) describes the fluid dynamic viscosity $\mu\left(T_{i}\right)$, as a polynomial function of fluid temperature $T_{i}$, the function parameters are adapted to fit data from table A-22 in (Cengel et al., 2008) (Properties of air at $1 \mathrm{~atm}$ pressure), the function is displayed in equation (10).

$\mu\left(T_{i}\right)=-3.0777 \times 10^{-11} T_{i}^{2}+4.8218 \times 10^{-8} T_{i}+1.7299 \times 10^{-5}$

For low $R e$, the flow is considered to be laminar, for higher $R e$, the flow is considered to be turbulent. In-between the laminar and turbulent region there is a region where the flow is called transitional flow. When the flow is transitional, the flow is frequently shifting between laminar and turbulent. The limits on $R e$ is shown in equation (11). (Cengel et al., 2008)

$$
\begin{cases}R e \leq 2300 & \text { Laminar flow } \\ 2300<\operatorname{Re}<10000 & \text { Transitional flow } \\ R e \geq 10000 & \text { Turbulent flow }\end{cases}
$$

Laminar and turbulent flow are the two flow characteristics that will be taken into account. The flow is mostly turbulent during the gas stand test performed, but the laminar region will be described to make the model complete.

\subsection{Friction Factor - Laminar Flow}

To calculate $f_{\text {pipe }, i}$ when the flow is laminar, equation (12) is used. (Cengel et al., 2008)

$$
f_{\text {pipe }, i}=\frac{64}{R e}
$$

\subsection{Friction Factor - Turbulent Flow}

During turbulent flow inside the pipe, the surface roughness of the pipe $\varepsilon$ affects the pressure loss inside the pipe (assuming pipe material to be stainless steel with surface roughness $\varepsilon=0.002 \mathrm{~mm}$ from table $14-1$ in (Cengel et al., 2008 ) during calculations). To calculate $f_{\text {pipe }, i}$ when the flow is turbulent, either equation (13), known as Colebrook equation, is used and iterated until $f_{\text {pipe }, i}$ is accurate enough, or equation (14) could be used. The result of equation (14) is within $2 \%$ of the result from equation (13). (Cengel et al., 2008)

$$
\begin{aligned}
& \frac{1}{\sqrt{f_{\text {pipe }, i}}}=-2.0 \log \left(\frac{\varepsilon / d_{i}}{3.7}+\frac{2.51}{\operatorname{Re} \sqrt{f_{\text {pipe }, i}}}\right) \\
& \frac{1}{\sqrt{f_{\text {pipe }, i}}} \cong-1.8 \log \left(\frac{6.9}{\operatorname{Re}}+\left(\frac{\varepsilon / d_{i}}{3.7}\right)^{1.11}\right)
\end{aligned}
$$

\subsection{Pressure Loss In Bend}

Pipe bends are treated as one-time losses, a smooth $90^{\circ}$ bend has a loss coefficient of $K_{L}=0.3$. The value of $K_{L}$ is strongly dependable on the type of pipe, size of bend etc., the coefficient value is found in table 14-3 in (Cengel et al., 2008), it is used to give a hint about how the losses affect the measured compressor efficiency. The pressure drop due to a pipe bend is calculated according to equation (15).

$$
\Delta p_{\text {bend }}=\frac{K_{L} v_{i}^{2} \rho_{i}}{2}
$$

\subsection{Pressure Loss in Inlet Nozzle and Outlet Diffuser}

Inlet nozzle and outlet diffuser can be used to connect the inlet and outlet pipes to the turbocharger. The inlet nozzle is treated as a convergent pipe, a convergent pipe is not inducing any pressure loss over the area change, other than the friction in the pipe. This is due to the contraction of the pipe, a gradually contracting pipe is normally not inducing any extra turbulence, other pressure losses than the pipe friction is normally neglected (Nakayama and Boucher. 1999), the pressure loss in the nozzle is neglected in this study (see equation (16b)). The friction loss in the inlet nozzle is assumed to be included in the pressure loss inside the inlet pipe. The outlet diffuser induces a pressure loss, due to the extra turbulence induced in the divergent region. The pressure drop in the outlet diffuser is calculated according to equation (16a), the pressure drop due to pipe friction is assumed to be included in the expression.

$$
\begin{gathered}
\Delta p_{\text {diffuser }}=\frac{K_{L, \exp } v_{i}^{2} \rho_{i}}{2} \\
\Delta p_{\text {nozzle }}=0
\end{gathered}
$$


The value of $K_{L, \exp }$ is found using tables, the used value is found in table 14-3 in (Cengel et al. 2008) (assumption of the diffuser angle $20^{\circ}$ results in $K_{L, \exp }=0.1$, when $d_{c, \text { outlet }} / d_{\text {outlet }}=0.8$ ). The fluid velocity inside the pipe $v_{i}$ is the fluid velocity at the diffuser inlet.

\subsection{Adjust Measured Data}

The measured data is adjusted by summarizing and withdrawing the pressure losses in the gas stand, from the measured values. The adjustments made are shown in equation (17a and (17b). The inlet and outlet total pressures are adjusted by adding or subtracting the pressure losses, depending on if the losses occur up or downstream from the measurement positions.

$$
\begin{aligned}
& p_{01}^{\prime}=p_{01}-\Delta p_{\text {pipe,inlet }}-\Delta p_{\text {bend }}-\Delta p_{\text {nozzle }} \\
& p_{02}^{\prime}=p_{02}+\Delta p_{\text {pipe,outlet }}+\Delta p_{\text {diffuser }}
\end{aligned}
$$

\subsection{Calculate New Compressor Efficiency}

The new corrected compressor efficiency is calculated using the total pressures that are adjusted to measurement data (see equation (17a) and (17b) and the measured total temperatures. The equation to calculate the corrected efficiency is the same as equation (2), but with the new corrected pressures $p_{01}^{\prime}$ ăand $p_{02}^{\prime}$ (see equation 18 ).

$$
\eta_{c}^{\prime}=\frac{\left(\frac{p_{02}^{\prime}}{p_{01}^{\prime}}\right)^{\frac{\gamma-1}{\gamma}}-1}{\frac{T_{02}}{T_{01}}-1}
$$

\section{Effect of pressure losses on mea- sured compressor efficiency}

Different simulation cases are performed to quantify the pressure losses main impacts on the measured compressor efficiency. The first case investigates the usage of straight inlet and outlet pipes, with the same diameter as the compressor inlet and outlet. The second case studies the usage of nozzle and diffuser on the inlet and outlet pipe, to connect a larger inlet and outlet pipe to the compressor. The third case is the same as the second, but a $90^{\circ}$ bend is added on the inlet pipe.

\subsection{Compressor and Pipes Dimensions}

A measured compressor map from a gas stand test is used to quantify the error in compressor efficiency due to the pressure drop between measurement positions and the turbocharger compressor. Compressor inlet outlet diameters and diameters at measurement locations are displayed in Table 11, these dimensions are needed to calculate the pressure drops in the different pipe sections. The results in Table 2 shows the maximum pressure loss over the different components. The inlet pipe is assumed to be $100 \mathrm{~mm}$ long and the outlet pipe is 3 or 10 times the outlet pipe diameter, both inlet and outlet pipe diameters are assumed to be the same as compressor inlet and outlet diameter when analyzing Case 1. According to SAE standard J1826 (SAE,
1995), the distance from the rotor down to the measurement location (if measuring static pressure) should be 2 to 3 pipe diameters downstream. In many pipe flows of practical engineering interest, the effects due to the entrance region become insignificant when the pipe length is longer than 10 pipe diameters (Cengel et al., 2008). Two different selections of outlet pipes lengths (10 and 3 times the outlet pipe diameter) are studied and compared in terms of measurement error due to the simulated pressure losses.

Table 1. Diameter of compressor inlet and outlet on the turbocharger, diameter on the inlet and outlet pipe at the measurement positions. Pipe lengths are assumed.

\begin{tabular}{ll}
\hline Measurement & Value \\
\hline$d_{c, \text { inlet }}$ (inlet compressor) & $56.5 \mathrm{~mm}$ \\
$d_{\text {inlet }}$ (measurement position $\left.p_{01}\right)$ & $58 \mathrm{~mm}$ \\
$d_{c, \text { outlet }}$ (outlet compressor) & $40 \mathrm{~mm}$ \\
$d_{\text {outlet }}$ (measurement position $\left.p_{02}\right)$ & $50 \mathrm{~mm}$ \\
$l_{\text {inlet }}$ & $100 \mathrm{~mm}$ \\
$l_{\text {outlet }}$ & \\
$3 d_{c, \text { outlet }}$ or $10 d_{c, \text { outlet }}$ & (case 1) \\
$3 d_{\text {outlet }}$ or $10 d_{\text {outlet }}$ & (case 2,3) \\
\hline
\end{tabular}

Table 2. Maximum pressure loss in the different components, for all 3 cases. The pressure losses are presented in Pascal.

\begin{tabular}{llllll}
\hline Case & $\Delta p_{\text {inlet }}$ & $\Delta p_{\text {outlet }}$ & $\Delta p_{\text {diff. }}$ & $\Delta p_{\text {bend }}$ & $\Delta p_{\text {nozzle }}$ \\
\hline 1 & 72 & 305 & 0 & 0 & 0 \\
1 & 72 & 1016 & 0 & 0 & 0 \\
2 & 71 & 315 & 1637 & 0 & 0 \\
2 & 71 & 1050 & 1637 & 0 & 0 \\
3 & 71 & 315 & 1637 & 803 & 0 \\
3 & 71 & 1050 & 1637 & 803 & 0 \\
\hline
\end{tabular}

\subsection{Case 1: Straight Pipes}

The first case investigates the use of straight inlet outlet pipes. Figure 5. Case 1, show the change in compressor efficiency for both short and long outlet pipe. In figure, it is visual that the pressure losses does not affect the compressor efficiency more than $0.8 \%$ (percentage points) at maximum mass flow of air when analyzing the long outlet pipe.

\subsection{Case 2: Pipes with Diffuser and Nozzle}

The diffuser and nozzle are used to either increase or decrease fluid pressure or velocity. The simulated inlet and outlet pipes with the pressure sensors mounted are assumed to have the same diameter as the pipe at the static pressure sensor location. The size of the diffuser is chosen to connect the pipe diameter where the pressure measurement is made, and the diameter of the compressor outlet. The results for both short and long outlet pipes are displayed in Figure 5, Case 2. Since the pressure loss 
caused by the nozzle is assumed to be zero, the pressure loss caused by the diffuser and the pipe friction causes the efficiency calculation error to be $1.4 \%$ (percentage points) when analyzing the short outlet pipe and up to $1.9 \%$ when analyzing the long outlet pipe.

\subsection{Case 3: Pipes with Diffuser, Nozzle and Bend}

A $90^{\circ}$ smooth bend is added to the simulated inlet pipe, between the pressure sensor and the pipe connecting to the compressor, to find its impact on the measured compressor efficiency, see Figure 5, Case 3. The pipe bend clearly affects the results, this is visual if comparing Case 2 with Case 3. The maximum error in the calculated compressor efficiency is $2.7 \%$ (percentage points), when analyzing the long outlet pipe.
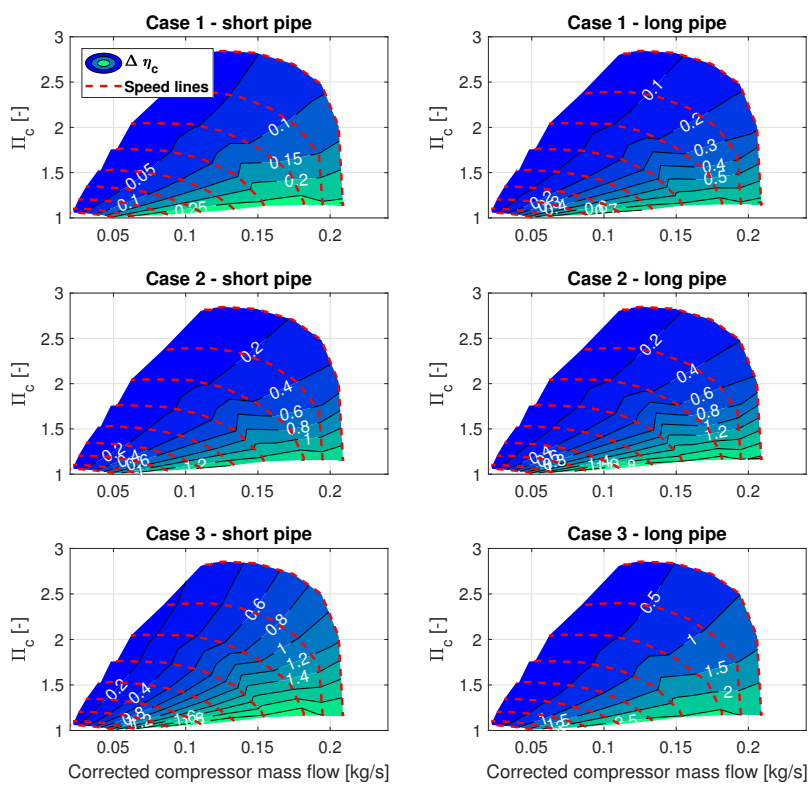

Figure 5. Displays the change in compressor efficiency $\Delta \eta_{c}=$ $\eta_{c}^{\prime}-\eta_{c}$ (color scale) compared against $\Pi_{c}$ and $\dot{m}_{c, c o r r}$. Short pipes corresponds to outlet pipe length equal to 3 times the pipe diameter, long pipes corresponds to 10 times the pipe diameter.
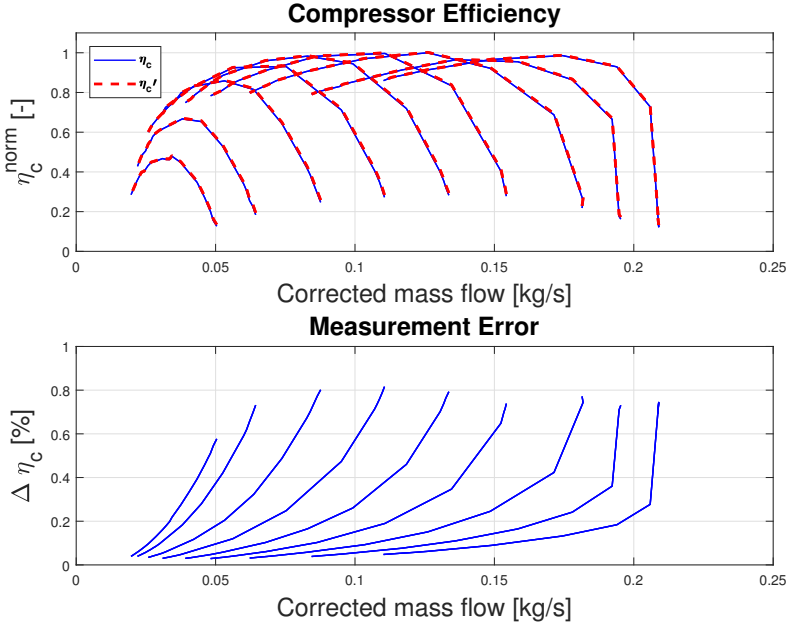

Figure 6. Case 1, the pipe length is 10 times the outlet pipe diameter. Top figure shows the normalized compressor efficiency with and without correction for the pressure losses in the gas stand, the bottom figure shows $\Delta \eta_{c}=\eta_{c}^{\prime}-\eta_{c}$.

\section{Summary and Discussion}

Three different cases have been investigated to find and quantify the error in compressor efficiency due to enthalpy change in the inlet and outlet pipes. The enthalpy change present between the pressure sensors and the compressor affects the compressor map the most in the high flow low pressure region, for each speed line. This is visible in both Figure 5 and Figure 6, For all the displayed cases, the error in compressor efficiency increases with increasing mass flow. Case 1 shows that a longer pipe between the compressor outlet and the measurement location induces larger error in measured compressor efficiency. Case 2 studies the use of pipes with nozzle and diffuser, the nozzle is assumed to not induce any pressure loss, which shows that the diffuser induces a large pressure loss, which affects the compressor efficiency. Comparing Case 2 with Case 3 , where the difference is the introduced pipe bend, clearly shows that a pipe bend induces errors in the calculated compressor efficiency. If a pipe bend is present between the pressure sensor and the compressor, it should be taken into account to correct measurements. The magnitude of the pressure losses in Table 2 are small, but they still affect the compressor efficiency noticeably.

\section{Future Work}

If this study is to be extended, one interesting aspect would be to investigate the impact on engine performance, if the compressor efficiency is corrected according to the study. The study could also be extended to take the heat transfer inside the inlet and outlet pipes into account.

\section{Conclusions}

For the selected set of gas stand physical dimensions, the change in compressor efficiency due to the calculated 
pressure losses is compared to original compressor efficiency calcuations. The results show:

- Due to the friction work, the enthalpy of the fluid between the pressure sensors and the compressor inlet and outlet changes.

- The measured compressor efficiency is lower than the actual efficiency, due to pressure losses between compressor and the pressure sensors.

- The induced error $\Delta \eta_{c}$ shows that the error is getting larger with increased mass flow for each speed line.

- If a $90^{\circ}$ bend is present between the measurement position and the inlet to the compressor, and the diffuser is connected on the outlet, the error in calculated compressor efficiency is up to $2.7 \%$ for compressor maximum mass flow with used parameters.

- The pressure losses in the inlet and outlet pipes are affecting the compressor efficiency most at the high flow low pressure region for each speed line, where the compressor efficiency is generally low.

\section{Acknowledgment}

This work was supported by the Vinnova Industry Excellence Center: LINK-SIC Linköping Center for Sensor Informatics and Control.

\section{References}

SAE Standard. J1826 - Turbocharger Gas Stand Test Code, 1995.

Yunus A. Cengel, Robert H. Turner, and John M. Cimbala. Fundamentals of Thermal-Fluid Sciences. McGraw-Hill, Singapore, 2008.

Lars Eriksson and Lars Nielsen. Modeling and Control of Engines and Drivelines. John Wiley and Sons Ltd, United Kingdom, 2014.

Erwann Guillou. Uncertainty and measurement sensitivity of turbocharger compressor gas stands. In SAE Technical Paper. SAE International, 04 2013. doi 10.4271/201301-0925 URL http://dx.doi.org/10.4271/ 2013-01-0925

Sathvick Shiva Kumar, Bert van Leeuwen, and Aaron Costall. Quantification and Sensitivity Analysis of Uncertainties in Turbocharger Compressor Gas Stand Measurements Using Monte Carlo Simulation. In SAE Technical Paper. SAE International, 04 2014. doi 10.4271/2014-01-1651 URL http://dx.doi.org/10.4271/2014-01-1651.

Silvia Marelli, Giulio Marmorato, Massimo Capobianco, and Andrea Rinaldi. Heat transfer effects on performance map of a turbocharger compressor for automotive application. In SAE Technical Paper. SAE International, 042015. doi:10.4271/2015-01-1287. URL http: / / dx . doi . org/ $10.4271 / 2015-01-1287$
Bernard Massey and John Ward-Smith. Mechanics of Fluids. Stanley Thornes, United Kingdom, 1998.

Y. Nakayama and R.F. Boucher. Introduction to Fluid Mechanics. Arnold, Great Brittan, 1999.

Nick Baines and Karl D.Wygant and Antonis Dris. The Analysis of Heat Transfer in Automotive Turbochargers. International Gas Turbine Institute of ASME, 2009. doi $10.1115 / 1.3204586$.

J. R. Serrano, V. Dolz, A. Tiseira, and A. Páez. Influence of environmental conditions and thermodynamic considerations in the calculation of turbochargers efficiency. In SAE Technical Paper. SAE International, 042009. doi $10.4271 / 2009-01-1468$ URL http: / / dx . doi.org/ $10.4271 / 2009-01-1468$

Giuliano Gardolinski Venson, Jose Eduardo Mautone Barros, and Josemar Figueiredo Pereira. Development of an automotive turbocharger test stand using hot gas. In SAE Technical Paper. SAE International, 112006. doi $10.4271 / 2006-01-2680$ URL http://dx.doi.org/ $10.4271 / 2006-01-2680$

Frank M. White. Fluid Mechanics. McGraw-Hill, Singapore, 1999.

Michael Y. Young and David A. Penz. The design of a new turbocharger test facility. In SAE Technical Paper. SAE International, 02 1990. doi:10.4271/900176 URL http: //dx.doi.org/10.4271/900176 